REVISTA ANDALUZA DE ANTROPOLOGÍA.

NÚMERO 4: ENCRUCIJADAS PARA LAS SOCIEDADES PESQUERAS DEL SUR EN EL MARCO DE LA GLOBALIZACIÓN. MARZO DE 2013

ISSN 2174-6796

[pp. 79-102]

http://dx.doi.org/10.12795/RAA.2013.i04.05

Fecha de recepción: 18/12/2012

Fecha de aceptación: 05/02/2013

\title{
LA PESCA ARTESANAL EN LAS ENCRUCIJADAS DE LA MODERNIZACIÓN. USOS, APROPIACIONES Y CONFLICTOS EN EL BORDE COSTERO DEL SUR DE CHILE
}

\section{Gonzalo Saavedra Gallo \\ Universidad Austral de Chile}

\section{Resumen.}

Observamos el borde costero del sur-austral chileno $-41^{\circ} 46^{\prime}$ y los $45^{\circ} 50^{\prime}$ latitud surcomo un espacio tensionado y en conflicto. Las principales tensiones se encuadran en los disímiles intereses por parte de los actores del territorio sobre los recursos hidrobiológicos que allí proliferan. Los conflictos, ciertamente recurrentes, se expresan en confrontaciones asociadas, por ejemplo, a la expansión de la industria salmonera en sectores que tradicionalmente fueron ocupados por la pesca artesanal; también en el marco de las asignaciones de cuotas de captura por parte de la Subsecretaría de Pesca y que, desde la perspectiva artesanal, benefician a los grandes empresarios; incluso conflictos entre pescadores debido a normativas que limitan el acceso a pesquerías de uso común, entre otros. Intentando compatibilizar estos y otros usos, las oficinas gubernamentales han impulsado, desde la década de 1990, un conjunto de medidas jurídico-administrativas y experiencias regionales de zonificación del borde costero. Ahora bien, el diseño y la aplicación de estos dispositivos no han estado exentos de controversia, incluso al punto de agudizar ciertos conflictos. Este trabajo analiza el proceso en cuestión, sugiriendo perspectivas críticas pero constructivas en orden a repensar la coexistencia relacional de los actores del borde costero en el sur de Chile.

Palabras clave. Borde costero, reglamentaciones, conflicto, pesca artesanal, actores. Abstract.

The coastal areas of southern and far-southern Chile (Latitude $41^{\circ} 46^{\prime}$ to $45^{\circ} 50^{\prime}$ South) give the impression of being under a great deal of social tension. The reasons for this 
tension are basically related to the dissimilar nature of the interests of the various stakeholders in the territory's abundant hydrobiological resources. The conflicts, which are unquestionably recurrent, give rise to confrontations associated, for example, to the expansion of the salmon farming industry into areas that traditionally have been used by artisanal fishermen. Another factor has to do with the fishing quotas assigned by the Under-Secretariat of Fisheries which, in the opinion of artisanal fishermen, clearly favors the large industrial fishing companies. There have even been disputes among fishermen caused, in part, by regulations that restrict access to common fishing areas. In an effort to juggle these -and other- uses, Government agencies have been promoting, since the 1990's, a number of legal / administrative measures as well as regional zoning initiatives for these coastal areas. However, the design and implementation of these measures have not been free of controversy, and in some cases, they have even stoked certain disputes. The present study examines the above processes and suggests some critical but constructive perspectives aimed at re-thinking the co-existence of the various players in the coastal areas of southern Chile.

Keywords. Coastal areas, regulations, conflict, artisanal fisheries, stakeholders.

\section{INTRODUCCIÓN ${ }^{1}$}

Desde tiempos prehispánicos el espacio costero sur-austral de Chile, en la Patagonia occidental, ha estado habitado por grupos recolectores del bordemar. En el decurso del tiempo, incluso hasta el presente, estos grupos -en realidad sus descendientes culturalescontinuaron allí asentados, no obstante los significativos procesos de mestizaje, hibridación y transformación material que se han sucedido. Asimismo ha sido y sigue siendo un territorio generoso en biodiversidad y abundante en recursos naturales con alta demanda en los mercados, nacionales y extranjeros. Esta última cualidad explica en parte los procesos de expansión económica acaecidos en el territorio desde mediados del siglo XIX, y que se hallan estrechamente asociados a dinamismos primario-exportadores, estratégicos en la economía chilena hasta el día de hoy. Entre las principales oleadas extractivistas cabe destacar la explotación de maderas nativas a fines del siglo XIX y principios del XX, la extracción artesanal de moluscos y otros recursos, cuyo destino han sido los mercados regionales y las plantas conserveras que procesan para distribución nacional y para exportación, y por último la explotación de la merluza austral (Merluccius australis), que se inicia a mediados de la década de 1980 para satisfacer principalmente la demanda del mercado español. En el núcleo de nuestro análisis tiene especial relevancia la expansión de la industria productora de salmones en cautiverio (en adelante IS), en

1. Este trabajo ha sido financiado por el Fondo Nacional de Desarrollo Científico y Tecnológico, proyectos Fondecyt no 11110542 y n $^{\circ} 1112204$. 
particular por sus impactos territoriales, económicos y socioculturales. En este sentido, y a diferencia de los otros procesos contemporáneos, la IS se encuadra en un proyecto deliberado de clusterización, conformando así parte de una estrategia de crecimiento que hermana en un mismo horizonte de sentido a empresarios y agentes del Estado.

Ladimensión conflictivadeesteespacioseexplicaporqueenélsecongregan relacionalmente diversos actores con disímiles usos, lógicas e intereses sobre sus abundantes recursos naturales, en particular marinos y paisajísticos. El escenario reseñado encuentra parte de su trasfondo institucional en las sucesivas decisiones político-administrativas que han organizado el acceso a los recursos y que, hasta cierto punto, han centralizado su gestión. Dicho lo anterior, el análisis aludirá a algunas de las "medidas" más influyentes en la vida económica local. En particular, como hito transversal, la "regionalización" del territorio nacional; la promulgación de la Ley General de Pesca y Acuicultura y los decretos de zona contigua; y en el caso particular de Aysén, la zonificación del borde costero.

Una forma de entender estas tensiones y conflictos es identificando a los principales actores y describiendo sus dinámicas relaciones. En particular entre Estado y pescadores artesanales, entre pescadores artesanales y empresas privadas (nacionales y transnacionales), y entre los propios pescadores artesanales. En la problematización del objeto en cuestión hemos recurrido a los trabajos de Pierre Bourdieu sobre los campos, en tanto espacios relacionales dialécticos, cuya estructuración revela diferenciales de poder condicionantes de esas mismas relaciones (Bourdieu, 1980; 2000). Teniendo en cuenta, por otro lado, la omnipresencia del Estado como entidad jurídico-normativa y decisiva en la matriz relacional, es destacable el valor heurístico que Norman Long (2007) asigna al concepto de interfaz, especialmente atingente si nos interesa retratar los intersticios etnográficos que matizan las posiciones y en especial las posibilidades de los actores en los procesos de desarrollo y en sus negociaciones. En efecto, como subraya el autor, esta aproximación permite un posicionamiento que relativiza el valor condicionante de la dialéctica estructural de los campos enfatizada por el propio Bourdieu. Por último, en el caso particular de los sistemas costeros, cabe citar la nomenclatura explicativa del "stakeholder approach" que, precisamente, permite explorar algunos factores críticos por ejemplo las distancias epistémicas entre los conocimientos locales y expertos- en contextos relacionales conflictivos asociados al manejo y co-manejo de pesquerías (Mikalsen y Jentof , 2001; Bennett, 2005; Cunningham, 2005; Berkes, 2009). En este ámbito nos interesa problematizar la complejidad que supone la articulación entre visiones de mundo disímiles, que frecuentemente se expresan en relaciones de poder en el espacio local y que, ciertamente, limitan la construcción de acuerdos y soluciones colectivas entre los actores involucrados (Berkes, 2009).

Este artículo se basa en una investigación doctoral realizada entre 2005 y 2010, que recientemente ha sido complementada con dos investigaciones financiadas por la 
Comisión Nacional Científica y Tecnológica de Chile (Fondecyt 11110542 y 1112204). Las tres investigaciones, de base etnográfica y documental, indagan en las respuestas de los sistemas pesquero-artesanales del sur-austral chileno en el marco de los procesos de modernización que se despliegan en sus territorios y que de diversos modos afectan su organización económica, social y política. El propósito de este artículo es sistematizar parte de la problematización trabajada en la investigación doctoral y anticipar algunos resultados parciales de las investigaciones en curso, principalmente en orden a visibilizar las configuraciones estratégicas y las respuestas que despliegan los actores locales -en particular pescadores artesanales- en estos escenarios modernizantes y constrictivos.

Metodológicamente el proceso de investigación se ha basado en sucesivas expediciones etnográfícas realizadas incialmente en 2004, 2006 y 2007, y retomadas en 2012. Se ha trabajado con bases de datos cualitativo-etnográficos (entrevistas y grupos de discusión), documentales y series estadísticas de desembarques artesanales y acuícolas.

\section{EL BORDE COSTERO COMO ESPACIO RELACIONAL}

\subsection{Antecedentes históricos}

La historia económico-social de las costas sur-australes se asemeja al devenir de otros territorios latinoamericanos. En realidad si hay una condición evidente, aun con sus particularidades, es su articulación a las dinámicas expansivas del capitalismo (Frank, 1967; Furtado, 1969). Ciertamente que la extracción/exportación de materias primas ha sido el motor de su dinamismo económico, el que debe observarse tanto en su diferenciación en distintas escalas geográficas como en sus lógicas de integración sistémica.

Una primera indicación estructural sugiere que este dinamismo económico extractivista fue especialmente funcional a los intereses primario-exportadores que prevalecen muy fuertemente, al menos en Chile, hasta la década de 1930 (Pinto, 1973; Sunkel, 1982). En este sentido, más que observar limitaciones y/o regulaciones, lo que encontramos son aperturas exportadoras en orden a favorecer la consolidación de economías centradas en la extracción de recursos naturales. Es más, las decisiones político-administrativas de entonces explícitamente contribuyeron al despliegue del proceso en cuestión.

Entre los principales elementos/procesos de la vida social y económico-cultural que fueron condicionando, desde mediados del siglo XIX, el devenir costero sur-austral, podemos indicar los siguientes. Primero, las relaciones asimétricas y de articulación entre la mano de obra nativa y los agentes externos, principalmente empresarios e intermediarios. Segundo, asociado a lo anterior, una presión extractivista que condicionó el comportamiento de esa fuerza de trabajo. Tercero, una dinámica expansiva que simultáneamente significó una progresiva diáspora chilota (habitantes de la isla de Chiloé) por todo el archipiélago patagónico y por Chiloé continental. Cuarto, una 
diáspora caracterizada por la instauración simultánea de varios oficios artesanales que no se limitaban a la práctica extractivista (procesado artesanal de pesquerías, elaboración de la madera, agricultura del bordemar). Cabe interpretar un entretejimiento económico que, si bien está muy condicionado por la presión exportadora, tiene unas dinámicas socio-culturales particulares.

Se estructura aquí una asimetría que a veces se expresa como tensión y otras como sumisión, tal vez como arquetipo relacional entre nativos y agentes externos, en especial estatales y empresarios nacionales (en principio, pequeños o medianos y pioneros en la explotación extensiva de estos recursos). Todo ello a la par con la instauración de una dinámica extractivista de larga data y con escasa regulación, al menos desde el punto de vista de la presión exportadora. A este respecto nuestra hipótesis es que los sistemas locales de base pesquero-artesanal en el archipiélago sur-austral, por su envergadura y racionalidad (reproductiva), tienden, en condiciones de baja presión de mercado, a la autorregulación; ahora bien, tal situación es cada vez más excepcional. Finalmente, debe señalarse que la citada dinámica de diáspora desde la Isla de Chiloé al sur, en especial desde fines del siglo XIX, va estableciendo una lógica de tránsito y ocupación del espacio costero, configurando una gran área económico-cultural. Esto tendrá consecuencias contemporáneas en el marco de las medidas regulatorias y de administración diferenciada de los territorios en cuestión.

\subsection{Perspectiva contemporánea}

El borde costero de los litorales del sur-austral de Chile constituye en la actualidad un espacio socio-cultural caracterizado por un alto dinamismo económico-productivo y sociopolítico $^{2}$. Lo anterior se enmarca en un modelo de desarrollo que, como antaño, potencia las dinámicas primario-exportadoras, ahora bajo la nomenclatura de los cluster estratégicos. Sobre todo es desde mediados de la década de 2000 que se viene pensando a nivel de las agencias de desarrollo y atracción de inversiones que el sur-austral, dadas sus "vocaciones económicas", debiera crecer y desarrollarse a partir de la consolidación de un cluster acuícola-salmonero (OCDE Chile, 2009). La apuesta es una dinámica virtuosa de productividad y crecimiento que en el mediano plazo tendrá efectos en la base social: ello, por supuesto, al margen de las particularidades y de la historicidad de las sociedades locales.

Ahora bien, el tejido empresarial no está constituido exclusivamente por salmoneros. En ese marco, una posición relevante y constrictiva la encontramos en las grandes compañías dedicadas a la exportación de pesquerías, ya sea semi-elaborado -como sucede con las

2. La región de Los Lagos tiene actualmente una población estimada de 850.000 habitantes, concentrando cerca del 35\% los pescadores artesanales de Chile (24.296), por su parte la región de Aysén tiene una población estimada de 105.000, de los cuales 3000 aprox. son pescadores artesanales. 
pesquerías demersales- o bien en conservería, como ocurre con parte importante de las pesquerías bentónicas ${ }^{3}$. En otras palabras, en las dinámicas relacionales del borde costero sur-austral, la industria pesquera y conservera también ejercen una presión significativa sobre la pesca artesanal. Esto ocurre de diversas maneras, por ejemplo en la disputa de las cuotas de captura en pesquerías comunes o, en términos más generales, en la demanda industrial por las pesquerías bentónicas y demersales de importancia comercial.

Cada uno de estos grupos de actores del espacio borde costero sur-austral es heterogéneo y diverso en su composición interna. De partida, el denominado "cluster salmonero" congrega a muchas empresas de diferente tamaño, algunas asociadas a la producción misma y a la exportación y otras subsidiarias de estas grandes compañías, relacionadas con la prestación de servicios, directos e indirectos. Incluso algunas de ellas son de origen local. Algo similar ocurre con las empresas vinculadas a la pesquería de la merluza austral y con las plantas conserveras emplazadas en los principales puertos del territorio en cuestión (Puerto Montt, Calbuco, Dalcahue, Quellón, Puerto Aysén).

Por su parte, los colectivos de pescadores artesanales, asentados en este vasto territorio, son también un referente central en el análisis, pero no sólo en su dinámica relacional con otros actores (empresas, Estado, universidades, ONGs), sino especialmente en su composición interna. De hecho una dinámica de alta conflictividad ocurre entre pescadores artesanales cuyas caletas se encuentran emplazadas en latitudes lejanas, y entre las cuales se han impuesto restricciones de acceso a pesquerías compartidas. Luego veremos que esto es muy evidente en el caso de la normativización de "zona contigua".

Ya advertíamos la diversidad y complejidad de la matriz relacional de actores que actualmente se despliegan sobre el borde costero sur-austral. No obstante, a los intereses de pescadores artesanales y comunidades locales y al tejido empresarial, debemos añadir la acción del aparato estatal vía programas específicos, especialistas de agencias sectoriales y ciertamente los marcos jurídicos, reglamentaciones y diseños de uso. Algunos tienen mayor peso legislativo, como la Ley General de Pesca y Acuicultura (promulgada en 1991), mientras que otros sólo son instrumentos consultivos, como es el caso de los planes de ordenación territorial o la zonificación de borde costero.

\subsection{Conflictos y dinámicas relacionales}

La definición jurídica de borde costero ha sido desbordada por las dinámicas que en

3. El Bentos refiere al grupo de organismos que, en forma permanente o semipermanente, se encuentran asociados al fondo marino, sobre él o semienterrados. La zona demersal corresponde a la columna de agua que está sobre el bentos, las especies demersales habitan esa columna de agua en permanente movilidad. 
él ocurren ${ }^{4}$. Las decisiones administrativas basadas en ese encuadramiento potencian su conflictividad como espacio relacional. Un ejemplo es la política de concesiones otorgadas a las empresas salmoneras sobre espacios marinos que tradicionalmente han sido utilizados por la flota pesquero-artesanal. Otro ejemplo es la regionalización de la pesca artesanal, que replica en el mar el modelo de administración del territorio nacional. En una expresión inédita, recientemente hemos constatado las tensiones que se suceden entre sindicatos de pescadores, que administran Áreas de Manejo y Explotación de Recursos Bentónicos (AMERB), y comunidades indígenas costeras del sur de Chiloé, que, bajo una nueva figura legal (Ley 20.249, 2008), están solicitando Espacios Costeros Marinos de Pueblos Originarios (ECMPO).

En nuestras investigaciones identificamos dinámicas relacionales de uso/apropiación del borde costero sur-austral. Estas dinámicas, que observamos bajo la perspectiva de un campo o subcampo del "desarrollo económico" localizado - adaptando el concepto de Bourdieu $(1980 ; 2000)$ - pero con alta incidencia económica transnacional, se caracterizan por el despliegue de una serie de tensiones y dialécticas, pero también flujos dialógicos, simbióticos y sinérgicos, que confrontan/relacionan a los actores aludidos más arriba. En la práctica hemos observado unas dinámicas relacionales generales y otras específicas, y que en su conjunto configuran y reconfiguran la estructura del campo en cuestión.

En cuanto a las dinámicas relacionales generales, habría que referir la tensión observada y territorialmente sentida en el marco expansivo de unos vectores de desarrollo modernizantes. Esto es, por un lado, asociado a los intereses empresariales (y también estatales) por continuar aprovechando la abundancia de recursos naturales costeromarítimos, que permitan mantener unos índices de crecimiento económico consistentes con un modelo de fuerte liberalización y apertura a los mercados internacionales. En otras palabras, es ese diseño estratégico de la política macroeconómica la que tensiona, desde una temporalidad unívoca, normativa y lineal, lo que el antropólogo Francisco Ther ha llamado los "territorios vividos" (Ther, 2011), condicionados culturalmente por otras lógicas/saberes/aprendizajes económico-productivos de uso/apropiación. Por otro lado, en una expresión complementaria de esta tensión modernizante, cabe analizar el despliegue del aparato político-institucional que va imponiendo fórmulas y/o soluciones a situaciones locales que, desde el juicio experto, observa como problemáticas (pobreza, ineficiencia, arcaísmo, etc.) y entiende que deben ser implementadas programáticamente. Pues bien, los espacios relacionales específicos que a continuación reseñamos se

4. "El Borde Costero del litoral es aquella franja del territorio nacional que comprende los terrenos de playa fiscales situadas en el litoral, la playa, las bahías, golfos, estrechos y canales interiores, y el mar territorial de la República, que se encuentran sujetos al control, fiscalización y supervigilancia del Ministerio de Defensa Nacional por medio de la Subsecretaría para las Fuerzas Armadas" (Comisión Nacional de Uso del Borde Costero). 
enmarcan en esas dimensiones del despliegue del campo. Y son precisamente este tipo de situaciones específicas las que retratarán el sentido controversial de las medidas de regulación y ordenación del espacio costero.

En el estudio de referencia (Saavedra, 2011), habíamos realizado este análisis diferenciando ocho espacios relacionales que en la práctica sintetizaban las dinámicas que ocurrían en otros cuarenta y ocho [micro] espacios situados en ocho localidades de pesca artesanal del litoral de la región de Aysén. En un ejercicio de abstracción, pero que mantiene una importante base etnográfica, proponemos volver a este análisis ampliando la perspectiva territorial hacia Chiloé y su entorno insular (ver mapa adjunto), pero admitiendo dinámicas específicas en cada uno de los tres siguientes espacios:

- $\quad$ El espacio relacional de la pesca artesanal bentónica con el Estado.

- El espacio relacional de la pesca artesanal bentónica a nivel regional y bi-regional.

- El espacio relacional de la pesca artesanal con la Industria del Salmón.

Dos de los tres casos que ilustran nuestra perspectiva analítica han sido tomados de pesquerías bentónicas. Esto no implica que otros sistemas -demersales o pelágicos-, no se vean afectados por las decisiones administrativas sobre el espacio borde costero y sobre los recursos en general; lo que sucede es que dada la naturaleza de localización y de relativa estaticidad de los recursos bentónicos, este tipo de decisiones -en particular aquellas referidas a la ordenación del espacio- resultan más sensibles en los sistemas de pesca artesanal con alto predominio de esas pesquerías. 

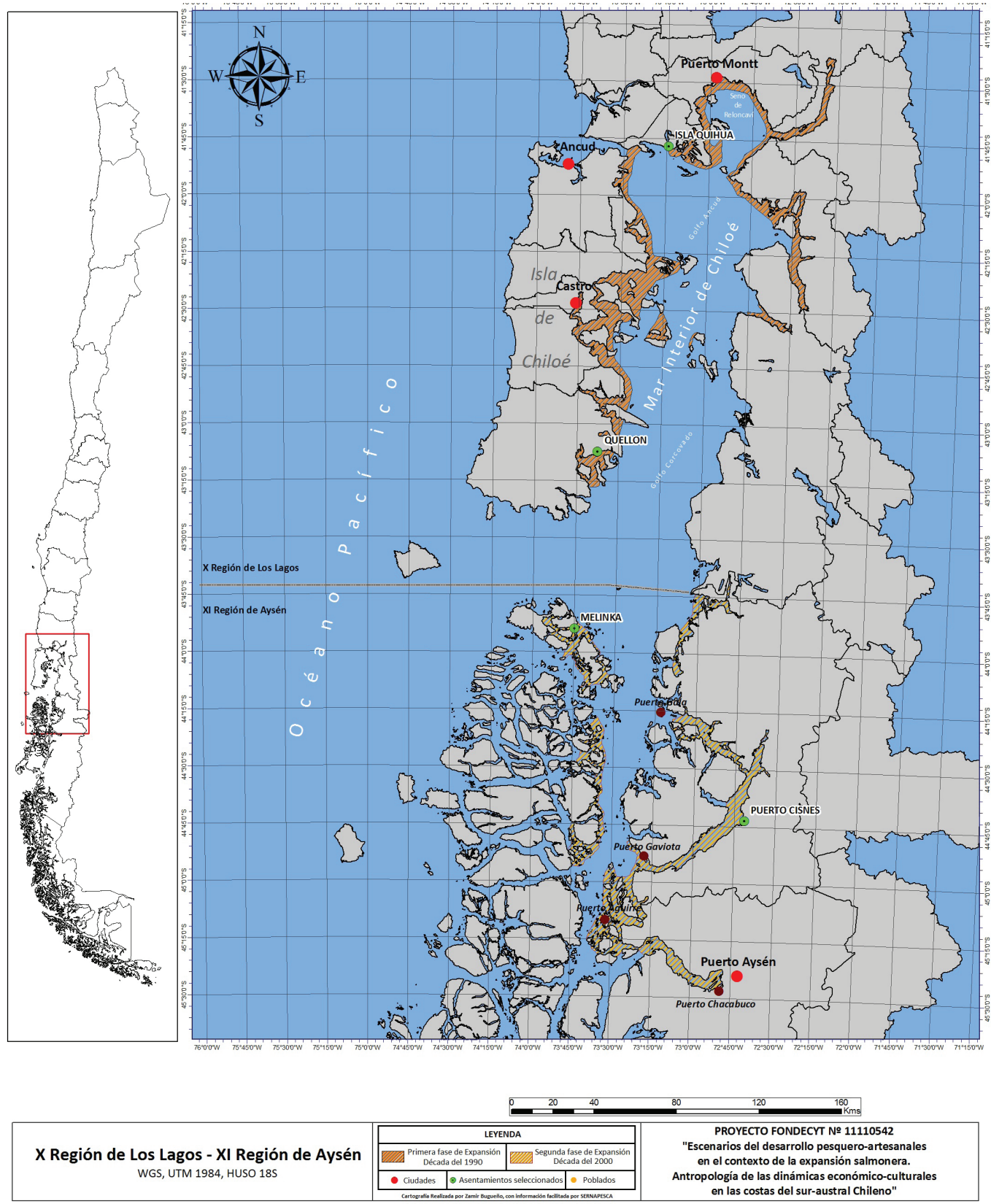

\subsubsection{Los actores en el territorio}

En los siguientes apartados se hará referencia a los espacios relacionales que congregan a los diversos actores del territorio. A modo de facilitar la comprensión del escenario en cuestión, haremos una breve reseña del mismo y de sus implicaciones más significativas. Territorialmente situamos nuestro objeto de investigación en la Isla de Chiloé y en sus áreas de influencia inmediata, esto es, por el norte, el archipiélago de Calbuco y, por el sur, el archipiélago de las Guaitecas. Si bien en el curso de nuestras investigaciones hemos realizado trabajo de campo en prácticamente todos los puntos del litoral sur-austral, el análisis que aquí se presenta tiene como referente las expediciones etnográficas realizadas en Isla Quihua (Calbuco), Quellón (sur de Chiloé), Puerto Melinka (norte de Aysén, 
Guaitecas) y en menor medida Puerto Cisnes y Puerto Aguirre (en la zona intermedia de la región de Aysén). Como puede advertirse en el mapa adjunto -cuyo sentido es señalar la tendencia y no graficar el cuadro exacto de la salmonicultura-, todas estas localidades se encuentran emplazadas en el área de expansión salmonera, condición que nos permite demarcar estos y otros asentamientos pesquero-artesanales como puntos conflictivos en un mapa económico que, conforme nos acercamos al "lugar" (Escobar, 2000), se torna crecientemente problemático. Lo que aquí proponemos es un análisis del conflicto en el marco de sus detonantes modernizantes, ello sin embargo no implica que se reduzca a ese único vector. No deben soslayarse los factores internos, propios de la coexistencia y convivencia social en el espacio compartido y particularmente en el marco del acceso a recursos comunes (Sánchez Fernandez, 1992; Pascual, 1996; Ostrom, 2000).

En Chile existen 87.289 personas inscritas en el Registro Pesquero Artesanal o RPA (SERNAPESCA, 2012), estimándose extraoficialmente que en torno a un 30\% no ejerce el oficio directamente y que sobre otro 30 o $40 \%$ lo hace fuera del sistema. En nuestra zona de estudio se concentra cerca del $40 \%$ del total de pescadores inscritos, observándose una importante diversidad en cuanto a oficio, infraestructura, equipamiento y artes de pesca, tipos de emplazamiento, apropiación del espacio y tradiciones culturales. Ahora bien, como veremos luego, un parámetro relevante es el tipo de especialización que tienen dentro del sistema. Bajo este criterio, incluidas ambas regiones, tenemos, al año 2012, 5.054 armadores, 6.087 buzos, 15.733 pescadores y 10.512 recolectores de orilla (SERNAPESCA, 2012). Lo anterior -sumando buceo y recolección de orilla- nos permite observar que se trata de un espacio de notoria importancia bentónica y que, por tanto, es particularmente sensible a las decisiones -normativas y regulaciones- que se establezcan sobre el borde costero.

\subsubsection{La pesca artesanal bentónica y el Estado en el borde costero sur-austral: límites regionales}

Puede advertirse que la composición sociocultural e institucional de cada uno de estos grupos de actores es heterogénea. En primer lugar porque, aun cuando son configuraciones mixtas, hay sistemas pesquero-artesanales con predominio bentónico y otros con predominio demersal, y en uno y en otro caso los usos/apropiaciones del borde costero son diferentes, del mismo modo que lo son las consecuencias y las respuestas frente a los procesos de regulación, gestión y ordenación que en él se establecen. Asimismo, en el caso de las agencias estatales y sus líneas programáticas la situación es diversa. Lo anterior se hace aun más evidente en la realización/aplicación práctica de la política pública, en especial en la interfaz que se despliega en cada dinámica relacional (Long, 2007).

Partamos del uso/apropiación bentónica del espacio en cuestión. Desde el Seno del Reloncaví hacia el sur, como se ha indicado, las comunidades de pescadores bentónicos 
están actualmente muy condicionadas/constreñidas por las decisiones administrativas tomadas a nivel de las agencias gubernamentales, en particular la Subsecretaría de Pesca y su entidad fiscalizadora, el Servicio Nacional de Pesca. Las tensiones y los dinamismos se explican, como marco general, en consideración al uso del espacio productivo/extractivo que tradicionalmente han practicado los asentamientos de base bentónica. Esto es, por un lado, un desplazamiento entre los bancos naturales por parte de las cuadrillas de buzos mariscadores y, por otro lado, el ejercicio de un trabajo extractivo localizado debido a que los bancos naturales tienen escasa movilidad en el fondo marino. Pues bien, esta cualidad de la pesca artesanal bentónica -que es predominantemente una actividad de buceo en profundidad (con un límite permitido de 20 metros) y largos desplazamientos por los litorales de ambas "regiones" - conforme ha sido regulada desde la matriz jurídica sectorial (Ley General de Pesca y Acuicultura, LGPA), se ha visto limitada en su movilidad. Por cierto que este no es el único punto controversial entre pescadores bentónicos y Estado, no obstante sí es uno de los más relevantes en términos de ordenación y administración de los territorios marino-costeros. Nos referimos específicamente a lo que denominamos la regionalización de la pesca artesanal, que en la práctica ha consistido en la aplicación de un criterio administrativo común a un conjunto de "regiones" muy diversas y que no necesariamente interpreta los condicionamientos socioculturales de los territorios gestionados por cada gobierno regional, bajo parámetros centralizados.

Pues bien, el criterio toma como premisa la división arbitraria del territorio chileno en quince regiones administrativas, cada una de ellas gobernada por un ejecutivo representante del gobierno central. La determinación de las quince regiones ha sido -desde su implementación gradual en 1974- una decisión geopolítica primero y tecnoeconómica después, procurando delimitar los territorios según sus caracteristicas geoespaciales y según sus "vocaciones" productivas objetivas (Boisier, 2007). Al promulgarse la Ley General de Pesca y Acuicultura, en 1991, se extendió dicho criterio al espacio marino-costero, de tal forma que cada región terrestre tiene su proyección hacia el mar, fragmentando adminsitrativamente la lógica tradicional del desplazamiento longitudinal de las flotas pesquero-artesanales. Es en ese sentido que la pesca artesanal en Chile se encuentra regionalizada. Esta regionalización, en el caso de los territorios meridionales, ha impuesto límites exógenos al desplazamiento de las flotas bentónicas que tradicionalmente han transitado entre el archipiélago de Calbuco por el norte y el vasto archipiélago de Aysén por el sur, incluso estableciendo faenas en la región de Magallanes. Desde nuestro punto de vista, el desplazamiento y la translocalidad constituyen parte de la matriz identitaria que desde tiempos remotos ha dado sentido a la pesca artesanal y, aunque resulte obvio, a las vidas navegantes del sur-austral.

Previendo en parte esta inconsistencia -sobre todo, observado como problema productivo- la LGPA contempla en su normativa la posibilidad de establecer un régimen 
de "zona contigua" a objeto de permitir el tránsito restringido de pescadores de una región administrativa hacia otra vecina: “[...]podrá extenderse el área de operaciones de los pescadores artesanales a la región contigua a la de su domicilio permanente y base de operaciones, cuando éstos realicen frecuentemente actividades pesqueras en la región contigua. Para establecer esta excepción, se requerirá de la dictación de una resolución de la Subsecretaría, previos informes técnicos debidamente fundamentados de los Consejos Zonales de Pesca que corresponda, con acuerdo de la mayoría de los representantes de la Región contigua del Consejo Zonal respectivo[...]" (LGPA 1991 Título IV, Art. 50).

En la actualidad sólo una zona contigua se encuentra autorizada en Chile, justamente en la frontera entre Chiloé y Aysén. En 2002, y luego en 2004, se autorizó a 508 buzos mariscadores, inscritos en los registros de Los Lagos, para realizar actividad de extracción de erizos (Loxechinus albus) y almejas (Venus antiqua) y Luga negra (Sarcothalia crispata) en la parte noroeste de Aysén. A continuación veremos que esta figura legal y su implementación -gestionada a través de una "pesca de investigación"- no han estado exentas de conflictos, en parte porque la imposición de límites jurídicos termina generando un efecto perverso en todo el sistema.

\subsubsection{La pesca artesanal bentónica a nivel regional y bi-regional: conflictos internos.}

En el punto anterior aludimos a la regionalización de la pesca artesanal, y en particular al decreto de zona contigua, como ejemplo de una medida administrativa que refleja, por un lado, la distancia entre las dinámicas de uso localizado y tradicional del espacio costero-marino y, por otro lado, los criterios que desde el nivel experto estatal imperan a la hora de establecer límites y regulaciones sobre la actividad. Con el fin de sintetizar esta situación, expondremos brevemente los principales componentes del escenario suscitado en el límite entre Los Lagos y Aysén (ver mapa adjunto).

De acuerdo a estudios arqueológicos, etnohistóricos e históricos, los grupos canoeros que habitaron los litorales del sur-austral se desplazaron entre la actual zona de Calbuco y los canales de la austral región de Magallanes (Martinic, 2005; Urbina, 2010). Ese temprano nomadismo sería recreado hasta nuestros días por los actuales pescadores artesanales, en particular bentónicos, emplazados tanto en Chiloé como en Aysén. Es más, en todos los relatos que hablan sobre el establecimiento de los principales poblados bentónicos del litoral aysenino (Melinka, Puerto Aguirre, Puerto Aysén) se alude a los lugares de origen de esos primeros migrantes que, sobre todo a principios del siglo XX, comenzaron a darle una fisonomía socialmente más sedentaria al gran archipiélago situado al sur del Golfo de Corcovado. Lo que evidencian esos testimonios es la estrecha conexión, incluso a nivel de relaciones de parentesco, entre los poblados costeros de Chiloé y Aysén. Los desplazamientos contemporáneos refrendan esta idea de una gran área económicocultural que, sin embargo, ha sido fracturada invocando una eficiencia administrativa más deseada que real. 
Consignemos que hoy en día -y en los últimos diez años- esto ha sido patente, al punto de erigirse una trama del conflicto a partir de ese artificioso límite. Ahora bien, aunque en particular la zona contigua es una medida que permite apaciguar en parte las tensiones culturalmente fratricidas ${ }^{5}$, está lejos de poder solucionar el problema de fondo: la toma de decisiones en abstracto y el diseño de soluciones escasamente situadas en sus contextos. Tal vez lo más inquietante en este caso sea el hecho y/o las consecuencias que los acuerdos de 2002 y 2004 no pueden normativizar, ni impedir. En particular el conflicto entre la flota bentónica de Guaitecas -beneficiada con el subsidio compensatorio por admitir a esos 508 buzos en sus costas- y la flota bentónica de Puerto Aguirre y Puerto Aysén, situada bastante más al sur y excluida de las compensaciones. Incluso en algún momento fueron acusadas/os por estos útimos de "vender" el litoral a la gente de Chiloé. Asimismo, aparecen las particularidades relacionales que denotan posiciones críticas respecto de la entrada al Litoral de "gente que no tiene historia aquí".

Citemos, sólo a modo de ejemplo, dos relatos obtenidos en el invierno de 2007 en Quellón (Chiloé) y en Puerto Aguirre (Aysén), pues en su contraste se refleja la tensión aludida. El primero corresponde a una entrevista realizada en el muelle artesanal de Quellón a uno de los dirigentes que participó activamente en la Comisión de Pesquerías Bentónicas (COMPEB), que en definitiva fue la instancia de negociación del acuerdo compensatorio. Le preguntamos qué pensaba sobre la posición de los pescadores de la región contigua:"[Es un] hecho... que los pescadores artesanales... que históricamente han hecho trabajos en la región contigua pueden seguir haciéndolo, bajo los regímenes que pueden llegarse a acuerdo, o bajo los regímenes que dicte la ley. Entonces, aparte de todo lo que te puedo decir hay un derecho histórico que yo te aseguro que la gente de la Décima región [se refiere a Chiloé, región de Los Lagos] que está trabajando en Guaitecas, no lo va a soltar así como así... Entonces mejor es un buen acuerdo que malos conflictos" (Entrevista a dirigente de sindicato de pescadores, Quellón, Julio de 2007).

El relato alude a los pescadores ayseninos, que por entonces mantenían un discurso y un accionar crítico respecto del acuerdo de explotación contigua de recursos tan importantes como el erizo y la almeja. En ese mismo trabajo de campo, estando en Puerto Aguirre establecimos contacto con una de las pocas mujeres que por entonces integraba uno de los sindicatos de pescadores artesanales de las islas Huichas. En su testimonio puede observarse una visión contraria, en particular respecto del error que habría cometido la

\footnotetext{
5. Desde fines de la década de 1990, y particularmente durante la primera mitad de los años 2000, se han suscitado una serie de conflictos entre pescadores artesanales de la región de Aysén y de Los Lagos. Ante el reclamo de estos últimos, y el consecuente rechazo de los primeros, invocando derechos históricos en las aguas australes, la expresión concreta de esos conflictos han sido tomas de caminos, cierre forzado de puertos, amenazadas de incendio en oficinas públicas, enfrentamientos localizados, entre otros.
} 
dirigencia de los artesanales de Puerto Melinka al aceptar el ingreso de los pescadores de Chiloé (Quellón) a las costas del norte de Aysén:“[Los dirigentes de Guaitecas] no le tomaron el peso a lo que estaban haciendo porque dejarles la puerta abierta, es como decirles 'oye, entren a mi casa, bárranla y después váyanse'. Porque ellos no dejan nada en la región, nada. O sea, ¿de qué le sirvió a Melinka? De nada, porque yo creo que ellos no ganan nada. No ganan progreso ni mejores precios, nada (Entrevista a socia de sindicato de pescadores artesanales, Puerto Aguirre, Agosto 2007).

Al tiempo que el acuerdo de zona contigua de 2004 está llegando a su ocaso, la experiencia demostró que -al margen del límite marítimo que separa ambas regiones y que fragmenta un área que históricamente fue apropiada como un espacio comúnlas dinámicas reales de uso/apropiación del espacio marino costero sur-austral son más fuertes que los límites impuestos. Aun así, vista y analizada la transgresión por los especialistas de la Subsecretaría de Pesca, la decisión administrativa no será del todo revertida, pues se ha comenzado a implementar una medida sustitutiva inspirada en una figura similiar a la pesca de investigación: Un plan de manejo que controle y restringa el acceso de pescadores de ambas regiones al espacio en disputa, en realidad se trata de una nueva forma de administrar la zona contígua o cualquier otro espacio bentónico que congregue a múltiples actores. La inspiración de este nuevo dispositivo administrativo -denominado Planes de Manejo para Recursos Bentónicos en Áreas de Libre Acceso (LGPA No 20560/2012)- ha sido, por una parte, el Enfoque Ecosistémico para Pesquerías y Acuicultura (Staples y Funge-Smith, 2009) y el citado enfoque de los Stakeholders, particularmente declarando la necesidad de avanzar hacia prácticas de co-manejo. Ahora bien, al menos hasta aquí, la cuestión de fondo sigue siendo, evidentemente, el supuesto tecno-científico respecto de la hipotética incapacidad de los propios pescadores artesanales para establecer sistemas de regulación exitosos. En realidad, creemos, es muy nítido el supuesto y el temor experto a la tragedia de los comunes (Hardin, 1968). Según Berkes (2009), uno de los principales problemas que se suscitan en este ámbito alude la desconfianza del "conocimiento científico" sobre el conocimiento local, imponiendo con ello una severa traba a los acuerdos de co-manejo y no legitimando la validez de esos saberes. Precisamente eso pareciera estar sucediendo en el caso de la nueva estrategia implementada en la zona contigua, ello en tanto la definición jurídica de los Planes de Manejo -y de las mesas participativas- explicita que la "investigación científica" es el criterio base para la toma de decisiones.

\subsubsection{La pesca artesanal y la Industria del Salmón en el borde costero sur-austral}

El análisis de este espacio relacional nos obliga a constatar las consecuencias e implicaciones que la expansión, crisis y el progresivo repunte que la Industria Salmonera ha tenido en los sistemas de pesca artesanal del sur-austral. Asimismo, nos impele a observar su incidencia en las decisiones expertas sobre el ordenamiento (zonificación) 
del borde costero en la región de Aysén. Partamos reseñando la dinámica expansiva que en los últimos veinte años ha tenido la IS en la zona en cuestión.

La expansión del cultivo de salmones en Chile no se explica exclusivamente por las fuerzas del mercado o producto de las inversiones privadas. En realidad podría hablarse de una simbiosis entre iniciativas privadas y estatales. De hecho entre 1969 y 1995, se desarrollan varios programas de cooperación con agencias internacionales -como la Japan International Cooperation Agency, JICA, - a objeto de transferir tecnología y formar capital humano (Fundación Chile, 1990). En esta misma línea, entre 1981 y 1984, agencias gubernamentales realizan estudios para "determinar la viabilidad económica y la factibilidad técnica del cultivo confinado de especies salmonídeas, lo que dio inicio a un proceso de adaptación de las técnicas utilizadas en Estados Unidos y en países escandinavos" (Claude y Oporto, 2000: 8). En 1988 los resultados eran concretos: mejoraba la productividad y se incrementaban las asesorías técnicas a la empresa privada. En 1995 se crea el Instituto Tecnológico del Salmón (INTESAL), con importantes aportes estatales a través de la Corporación de Fomento de la Producción (CORFO).

Durante las últimas dos décadas, en consonancia con el interés expresado en las iniciativas reseñadas, los distintos gobiernos que se han sucedido en el poder han priorizado en su política de desarrollo territorial el crecimiento de la IS, como cluster estratégico para la zona sur-austral (Pérez-Alemán, 2005; OCDE Chile, 2009). Ahora bien, la clave de esta decisión ha sido asegurar a los inversionistas un clima de estabilidad política, flexibilidad laboral y unas mínimas restricciones para expandir centros de cultivo en uno de los ecosistemas más prístinos del hemisferio $\operatorname{sur}^{6}(5)$.

A fines de los años noventa el cultivo de salmones era un negocio de tal magnitud y prosperidad, que prácticamente la totalidad del borde costero interior de la isla de Chiloé, el Estuario de Reloncaví y gran parte del entorno de la ciudad de Puerto Montt, estaban saturados de centros de engorde. En ese marco se proyectó una segunda fase expansiva, y es así como en la década de 2000 comienzan a proliferar las jaulas de cultivo en los canales y fiordos ayseninos, sobre todo en zonas aledañas a Puerto Melinka, Puerto Cisnes y a Puerto Chacabuco. Debe destacarse además que el marco legal de la acuicultura industrial, contenido en la LGPA, ha sido un instrumento de gestión administrativa fundamental, pues da toda clase de facilidades y garantías a los inversionistas. Reflejo de lo anterior es la mega-concesión del archipiélago de Chiloé en los años noventa y de los archipiélagos de Aisén en la década de 2000.

6. Los procesos de zonificación del borde costero, sobre todo en las tres regiones australes, se enmarcan en la necesidad de ordenar las actividades productivas en unos litorales altamente presionados por la avanzada de la industria acuícola, la IS en particular. Aysén, a partir de 2000, fue parte de las tres experiencias piloto a nivel nacional. 
Si bien no hubo una demanda explícita y sostenida por parte de los pescadores artesanales, ni de Chiloé ni de Aysén, respecto de las concesiones solicitadas por la IS, y en general respecto de su expansión, ello no impidió que a principios de la década de 2000 se iniciará un ambicioso proceso de zonificación y microzonificación del borde costero de la región de Aysén. En realidad, al margen de la presión de algunos ambientalistas, las autoridades del Gobierno Regional advirtieron que de no establecerse normas claras y comunes, el borde costero regional podría en el mediano plazo padecer una saturación similar a la de la isla de Chiloé. En ese contexto, se decidió instalar una mesa de trabajo que congregara a todos los actores con intereses litoraleños. Pues bien, en el curso de dos años la mesa -con asesoría técnica de la Agencia Alemana de Cooperación Técnica, GTZ (Deutsche Gesellschaft für Technische Zusammenarbeit)- propuso una distinción de áreas en todo el borde costero de Aysén, dejando prácticamente la mitad del archipiélago como zona apta para actividades de acuicultura (AAA), unas 500.000 hectáreas. Más allá de que en Chile no existe una ley de ordenamiento territorial, y más allá de las suspicacias y críticas que desató esa propuesta inicial (no reconocía cabalmente las zonas históricas de uso pesquero-artesanal) es indudable que favoreció significativamente los intereses privados y un horizonte de crecimiento prácticamente ilimitado.

Hasta mediados de 2007, sostenidamente la IS registró indicadores económicos muy favorables. Por ejemplo entre 1990 y 2000 las exportaciones netas de salmón cultivado se multiplicaron por cinco, pasando de 26.000 a 271.500 toneladas (CORFO, 2002), para llegar en 2005 a las 383.700 toneladas (Salmonchile, 2007). Si en 1995 las exportaciones de salmones y truchas ascendían a 489 millones de dólares, para 2005 esa cifra llegó a los 1.721 millones de dólares. Después de Noruega, Chile ha sido, desde 1995, el segundo productor mundial de salmones y su objetivo a mediano plazo era convertirse en el primero. Cabe destacar además la importancia estructural comparativa que la producción de salmones y truchas llegó a tener en los años previos a la crisis. Rodrigo Infante, entonces presidente de SalmonChile, sostenía que las exportaciones de Salmón representaban un 30\% del PIB total de las regiones de Los Lagos y Aysén, además de un 75\% de sus exportaciones (Infante, 2008). No obstante, a partir de 2008 la situación cambiaría dramáticamente y la conjunción de dos factores explica la debacle. Por una parte, la crisis financiera de 2007 y 2008 obliga a bajar las expectativas de crecimiento pero, sobre todo, como segundo factor, sobreviene una crisis sanitaria interna. En el marco de la obsesión por competir y crecer, la salmonicultura chilena comienza a ser afectada por una serie de enfermedades asociadas a las condiciones de producción que intentan optimizar rendimientos bajando costos y estándares ambientales. Una de esas enfermedades, la Anemia Infecciosa del Salmón o virus ISA, afectó a la especie Salmón Atlántico, una de las principales en todos los centros de cultivo. La crisis tuvo tal impacto que en los ciclos inmediatos se registra una caída de la producción cercana al 50\% y mientras el empleo asociado cae en el orden del $60 \%$. La siguiente tabla refleja la situación descrita. 


\begin{tabular}{|l|r|r|r|r|r|}
\hline ESPECIE & \multicolumn{1}{|c|}{2006} & \multicolumn{1}{l}{2007} & \multicolumn{1}{l|}{2008} & \multicolumn{1}{l}{2009} & \multicolumn{1}{c|}{2010} \\
\hline \multirow{2}{*}{ Salmon del Atlántico } & 300.065 & 231.573 & 248.971 & 72.499 & 37.105 \\
\cline { 2 - 6 } Salmon plateado & 87.193 & 74.696 & 72.212 & 93.891 & 90.924 \\
\cline { 2 - 6 } Salmon rey & 1.958 & 1.910 & 72 & 595 & 636 \\
\cline { 2 - 6 } Trucha arco iris & 110.296 & 105.991 & 91.760 & 95.156 & 165.313 \\
\hline TOTALES & $\mathbf{4 9 9 . 5 1 2}$ & $\mathbf{4 1 4 . 1 7 0}$ & $\mathbf{4 1 3 . 0 1 5}$ & $\mathbf{2 6 2 . 1 4 1}$ & $\mathbf{2 9 3 . 9 7 8}$ \\
\hline
\end{tabular}

Tabla 1. Desembarques IS, Región de Los Lagos, 2006 - 2010. Fuente: Servicio Nacional de Pesca, anuarios estadísticos.

Lo reseñado, además de dar cuenta de la magnitud que ha tenido la IS en la zona suraustral, deja en evidencia que su principal criterio de regulación ha sido el mercado, lo que ciertamente ha derivado en un modelo de crecimiento perverso con escasa capacidad de control sobre sus consecuencias. No estamos aquí demasiado lejos del cuadro más pesimista que nos retrataba hace algunos años la sociología del riesgo, en el marco de la crisis ecológica y de producción en la Europa de la modernidad tardía (Bauman, 1996; Beck, 1997 y 1999; Giddens 1999). En una reciente investigación, Beatriz Bustos (2012) ha evidenciado el fracaso de la matriz público-institucional para articular el conocimiento científico en la resolución y manejo de la crisis producida con la propagación del ISA en Chiloé. Asimismo ha llamado la atención sobre la incapacidad de la propia comunidad científica para instalar el tema (de la sustenatibilidad) en la agenda público-privada.

Simultáneamente la dimensión expansiva de la IS -expresada en indicadores estadísticos como en una progresiva transformación modernizante del espacio local y del territorioimplica también unos impactos y unas respuestas localizadas en la vivencia subjetiva e intersubjetiva de unos actores cuya vida social y económico-cultural se ha ido construyendo "desde siempre" en ese espacio local y en esa territorialidad y, por qué no decirlo, en el arraigo de ciertas tradiciones que no por dinámicas son indiferentes a tan vigorosa avanzada transnacional. En otras palabras, los sistemas pesquero-artesanales en toda la costa sur-austral reconocen y re-elaboran, desde la subjetividad reflexiva/ imaginativa de sus habitantes, tanto las consecuencias objetivas de la expansión de la IS como los significados y las perspectivas que para ellos/as implica en sus propios sistemas de vida y de reproducción material. 
En términos amplios, a modo de caracterización, estos sistemas pesquero-artesanales son diversos y heterogéneos: algunos son de base bentónica (como Puerto Melinka y Quellón), la mayoría especializados en la extracción de erizos (Loxechinus albus), almejas (Venus antiqua, Gari solida), algas -lugas roja y negra- (Gigartina skottsbergii y Sarcothalia crispata), mejillones (Mytilus chilensis), entre otras especies. Otros de marcado predominio demersal (como Puerto Cisnes y en general como toda la costa continental), en particular especializados en capturas de merluza austral (Merluccius australis) y en menor medida congrio (Genypterus sp) y otras especies eventuales. Encontrando además, particularmente en Chiloé, una importante flota pelágica pero que en muchos casos opera con capitales empresariales. Como se ha indicado más arriba, la composición económico-productiva de estos sistemas pesquero-artesanales tiende a ser mixta. Observamos por ejemplo una integración tradicional con actividades de agricultura campesina (Chiloé, Calbuco, Reloncaví), también una relación estrecha -extractiva, por cierto- con el bosque nativo (costa aysenina), y en todos los casos una creciente importancia y presencia de las industrias pesquera y sobre todo salmonera.

Este último aspecto revela en parte la complejidad del escenario. En primer lugar porque los sistemas tradicionales del bordemar, incluyendo por supuesto a la pesca artesanal, se encuentran inmersos en dinámicas de interrelación permanente con otros actores económicos e institucionales (empresas, intermediarios, agencias públicas, ONGs, universidades, etc.); y en segundo lugar porque esas dinámicas suponen interrelaciones que, a la par de unas capacidades de resistencia creativa (García Canclini, 1990; Barkin 2002), negociación (Long, 2007) y reinvención de los proyectos modernizantes (Escobar, 1996; 2000), también suponen procesos de descomposición estructural, articulación, occidentalización y subordinación a los "propósitos" expansivos del capital (Godelier, 1990; Friedman, 1994; Comas, 1997). Sin desconocer que un mercado altamente liberalizado, como ocurre en Chile, actúa como vector disolvente de sistemas de producción local, advertimos que la cuestión no se reduce al determinismo estructural; más bien constatamos -especialmente en la tensión comunidad de pescadores/empresas salmoneras- una diversidad relacional cuya complejidad estriba, entre otros factores, en la capacidad local para consolidar respuestas económicas y ambientales -es decir, políticas- frente al avance modernizador y en las dificultades para establecer acuerdos basados en un entendimiento comunicacional entre actores locales y externos (Berkes, 2009). Cabe subrayar, asimismo, que las flotas pesquero-artesanales han ido cambiando sus configuraciones internas, evidenciando la internalización de lógicas que -en un esquema convencional- asociaríamos a la racionalidad mercantil, pero que, sin embargo, tienden a estar cada vez más presentes en el sistema (Galván y Pascual 1996; Florido del Corral 2003 y 2008). Es evidente que el modelo dicotómico, y/o modernizante clásico, resulta insuficiente para observar los escenarios contemporáneos de la pesca artesanal. Nuestra experiencia etnográfica en el sur-austral de Chile, revela tanto la diversidad 
de expresiones pesquero-artesanales, en el sentido tradicional, como la complejidad también variable de sus vinculaciones con el mercado, con las instituciones en general y con otros actores locales de su entorno.

En las expediciones etnográficas realizadas a Puerto Melinka y a Quellón (2006 y 2007) y a Puerto Cisnes, luego a Calbuco y nuevamente a Quellón (2012), constatamos una diversidad de posiciones condicionadas por el tipo relación que las personas entrevistadas han tenido con las salmoneras. Estas posiciones discursivas varían en tres niveles, entre la crítica moderada y la radical; y en otro registro, entre la valoración favorable y la valoración relativa. En todos los casos hay un importante condicionamiento según quien reflexiona y desde qué experiencias con la IS. En la crítica moderada se reconoce la generación de empleo al tiempo que se advierte la contaminación, visión que se radicaliza al añadir el problema de la pérdida de espacios y el escaso aporte a las economías locales: “...la biomasa... se fue perdiendo con el tema del salmón, [se] fue perdiendo... [la] pesca del róbalo, por las contaminaciones puede ser que se vaya perdiendo eso. Nos van quitando espacio a nosotros, quitándonos espacio... se están adueñando de todo lo que es las costas, los lugares, ya no [se] puede pasar cerca de ellos... Cada vez nos estamos viendo más perjudicados por ese lado... [por] el tema de que nosotros nos ganamos la vida en el mar" (Entrevista a pescador artesanal, Puerto Cisnes, enero 2012).

Las valoraciones favorables destacan la generación de empleo y la aparición de nuevas oportunidades: "La empresa salmonera siempre es una fuente de trabajo para la gente que no trabaja en pesca artesanal. Yo creo que toda empresa es buena en el sentido que da trabajo a la gente y tiene un montón de buenas cosas. Y con respecto a la contaminación, toda empresa va a contaminar, sea buena o sea mala" (Grupo de discusión, mujer operaria de planta de salmones, Isla Quihua, Calbuco, abril 2012).

En general hay una visión optimista que tiende a subordinar lo negativo a las posibilidades que la IS abre en espacios económicos aislados y tradicionales.

En el análisis del material empírico, llama nuestra atención una capacidad reflexiva crítica de la población local respecto de las consecuencias y el significado de la expansión radical de la IS por todo el sur-austral. Por otra parte, aparejada a esa reflexividad local, una recurrente tendencia a imaginar soluciones y/o alternativas al problema de la expansión (espacial) de la IS. Esto lo hemos constatado en todas las localidades en donde realizamos trabajo de campo. Planteadas como futuros deseados y factibles, las principales alternativas señaladas en las entrevistas pueden agruparse en las siguientes proyecciones: 1) De diversificación extractiva, pues hoy la tendencia es monoextractiva, en parte por la constricción mercantil y las restricciones del RPA;2) De procesamiento o conservería, por cierto son recurrentes las experiencias artesanales en todas las localidades pero están fuera de normativa sanitaria; 3) De capacidad comercializadora, en donde observamos una fuerte presencia de intermediarios y de estratificación organizacional 
(dirigentes que se hacen intermediarios); 4) De consolidación de las áreas de manejo, fórmula administrativa impuesta por SUBPESCA pero reformulada desde las prácticas local y, en algunos casos, desde los usos consuetudinarios; 5) De actividades turísticas, con muy pocas iniciativas vigentes; 6) De cultivos artesanales, en el caso de los mitílidos hay algunas experiencias exitosas en Chiloé y en el Estuario del Reloncaví.

Si bien ninguna de estas "respuestas" supone acciones directas sobre la expansión de la IS, en todos los casos constituyen parte de escenarios imaginados como alternativos a su predominio. Asimismo prevalece una visión que compatibiliza, en un mismo horizonte de futuro, una industria regulada desde el Estado y un desarrollo integral de los sistemas de pesca artesanal.

Este tipo de observaciones/respuestas, que son bastante coincidentes a pesar de las distancias entre unas y otras localidades, dan cuenta de unos saberes pesqueros (Gajardo y Ther, 2011) y de unas capacidades e inteligencias culturales locales (Saavedra y Macías, 2012) desaprovechadas por parte de los sistemas expertos instalados en el Estado, que más bien tienden a favorecer dinámicas desreguladoras y a transferir dispositivos sofisticados que no siempre se condicen con otras formas de habitar los espacios marino-costeros.

\section{CONCLUSIONES}

Una conclusión convencional y evidente podría énfasis en la dialéctica de lo tradicional y lo moderno, en donde lo tradicional, sobre todo observado en sus dinámicas de uso/ apropiación del espacio costero, desborda constantemente las rígidas nomenclaturas normativas que la administración impone para asegurar eficiencia económica y sustentabilidad. En realidad, subordinando la segunda a la primera. Tal vez en este nivel de la problemática, deba insistirse en la dudosa virtud de las soluciones generales y uniformes para situaciones diversas, particulares y localizadas. Ya lo advertía Elinor Ostrom (2000) al constatar lo innecesariamente difícil que sería imponer unas reglas para sustituir otras reglas, en no pocos casos más eficientes en la gestión de recursos comunes, aunque particulares y de base tradicional. Porque tal vez en ello estribe el meollo de la cuestión: lo que observamos en los litorales sur-australes es una dinámica expansiva de la modernización (por ejemplo, económica e institucional), que apuesta por sustituir aquella matriz tradicional instalando otros órdenes lógicos aplicables al habitar el territorio y en consecuencia hacerlo funcional a los grandes propósitos del crecimiento económico, entendido desde la perspectiva neoclásica. Incluso, previamente, merece la pena poner en entredicho la condición de la naturaleza como "recurso". No deja de ser sugerente el llamado de atención que Enrique Leff (2002) nos hace respecto de las denominaciones que utilizamos, por ejemplo, al decir "capital natural" y la instrumentalización que ello implica.

Ahora bien, tampoco se trata de suponer la existencia de unas formas puras y genuinas 
de relacionarse con el espacio y los recursos. En realidad lo que encontramos conforme transcurre el tiempo, en algunos casos, es una reinvención transgresora y/o creativa de esos dispositivos expertos, incluso la internalización progresiva y/o parcial de sus lógicas (Florido del Corral, 2003). No obstante hay también una dimensión intersubjetiva, reflexiva e imaginativa local, en donde, creemos, reside la potencia analítica experiencial para rediseñar las soluciones transferidas. No hay aquí necesariamente una ineludible derrota de lo local frente al proyecto modernizador. 


\section{REFERENCIAS BIBLIOGRÁFICAS}

Barkin, David (2002) "El desarrollo autónomo: un camino a la sostenibilidad". En Héctor Almodinda (Comp.), Ecología Política. Naturaleza, sociedad y utopía. Buenos Aires: CLACSO, pp.169-202.

Bauman, Zigmunt (1996) "Modernidad y ambivalencia". En Jostxo Beriain (Comp.) Las consecuencias perversas de la modernidad. Barcelona: Anthropos, pp. 73-119.

Beck, Ulrich (1997) "La reinvención de la política: hacia una teoría de la modernización reflexiva”. En Beck, U., Giddens, A. y Lash, S, Modernización Reflexiva. Madrid: Alianza, pp.13-74.

Beck, Ulrich (1999) La sociedad del riesgo global. Madrid: Siglo XXI.

Benett, Elizabeth (2005) "Success in Fisheries Management: A Review of the Literature". En Stephen Cunningham y Tim Bostock (eds.) Successful Fisheries Management. Issues, Case Studies and Perspectives. Amsterdam: Eburon, pp. 21-43.

Berkes, Fikert (2009) "Evolution of co-management: Role of knowledge generation, bridging organizations, and social learning". Journal of Enviromental Management, 90, pp. 1692-1702.

Boisier, Sergio (2007) La regionalización en Chile: ¿Quo Vadis?. Lima: Mimeo.

Bourdieu, Pierre (2000) Las estructuras sociales de la economía. Barcelona: Anagrama. Bourdieu, Pierre (1980) El sentido práctico. Madrid: Taurus.

Bustos, Beatriz (2012) "Brote del virus ISA: crisis ambiental y capacidad de la institucionalidad ambiental para manejar el conflicto". EURE, 38 (115), pp. 219-245.

Comas D’Argemir, Dolors (1997) Antropología económica. Barcelona: Ariel.

CORFO (2002) Identificación y Análisis de oportunidades de inversión para la Región de Aysén, Chile. Corporación de Fomento de la Producción. Coyhaique: Agencia de Atracción y Promoción de Inversiones TODO CHILE.

Cunningham, Stephen (2005) "Factors ofr Success in Fisheries Management". En Stephen Cunningham y Tim Bostock (eds) Successful Fisheries Management. Issues, Case Studies and Perspectives. Amsterdam: Eburon, pp. 233-238.

Escobar, Arturo (2000) "El lugar de la naturaleza y la naturaleza del lugar: globalización o posdesarrollo". En Andreu Viola (comp.) Antropología del desarrollo, Teorías y estudios etnográficos en América Latina. Barcelona: Paidós.

Escobar, Arturo (1996) La invención del Tercer Mundo. Construcción y deconstrucción del desarrollo. Bogotá: Norma. 
Florido del Corral, David (2008) "Las flotas artesanales andaluzas en un contexto de crisis”. En Fernando González Laxe (ed) Lecciones de economía pesquera. La Coruña: Netbiblo, pp. 267-298.

Florido del Corral, David (2003) "Las flotas artesanales andaluzas en la era de la "glocalización": desafíos teóricos y prácticas de un proceso conflictivo". Zainak, 25, pp. 195-216.

Frank, André G. (1967) Capitalismo y subdesarrollo en América Latina. México D.F.: Siglo XXI.

Friedman, Jonathan (1994) Identidad cultural y proceso global. Buenos Aires: Amorrortu.

Furtado, Celso (1969) La economía latinoamericana desde la conquista ibérica hasta la revolución cubana. México D.F: Siglo XXI.

Gajardo, Claudio y Ther, Francisco (2011) "Saberes y prácticas pesquero-artesanales: Cotidianeidades y desarrollo en las caletas de Guabún y Puñihuil, Isla de Chiloé". Chungara, Revista de Antropología Chilena, 43 (número especial), pp. 589-605.

Galván, Alberto y José Pascual (1996) "Pescadores: las sociedades de pescadores y la antropología”. En Joan Prat y Ángel Martínez (eds.) Ensayos de Antropología Social: Homenaje a Claudio Esteva Frabregat. Barcelona: Ariel, pp. 128-138.

Giddens, Anthony (1999) Un mundo desbocado. Madrid: Taurus.

Godelier, Maurice (1990) Lo ideal y lo material. Madrid: Taurus.

Hardin, Garret (1968) “The Tragedy of the Commons”. Science, 162, pp. 1243-1248.

Infante, Rodrigo (2008) Industria del Salmón en Chile: Un ejemplo de Innovación. Chile: Asociación de productores de salmones y truchas, Salmon Chile A.G..

Leff, Enrique (2002) Saber ambiental. Sustentabilidad, racionalidad, complejidad, poder. México D.F.: Siglo XXI.

Long, Norman (2007) Sociología del desarrollo: una perspectiva centrada en el actor. México D.F.: COLSAN - CIESAS.

Martinic, Mateo (2005) De la Trapananda al Aysén. Una mirada reflexiva sobre el acontecer de la Región de Aysén desde la Prehistoria hasta nuestros días. Santiago: Pehuén.

Mikalsen, Knut H. y Jentoft, Svien (2001) "From User-Groups to Stakeholders? The Public Interest in Fisheries Management”. Marine Policy 25(4): 281-292.

Ministerio de Economía (1991-2012) Ley General de Pesca y Acuicultura. Valparaíso: División Jurídica Subsecretaría de Pesca.

OCDE Chile (2009) Estudios Territoriales de la OCDE. Chile. Santiago: Ministerio del Interior, Gobierno de Chile. 
Ostrom, Elinor (2000) El Gobierno de los bienes comunes. La evolución de las instituciones de acción colectiva. México D.F: Fondo de Cultura Económica.

Pascual, José (1996) "El paradigma de la tragedia de los comunes y el caso de los pescadores". En M. Neölle Chamoux y J. Contreras (eds) La gestión comunal de los recursos. Economía y poder en las sociedades locales de España y América Latina. Barcelona: Icaria. pp. 143-148.

Pérez-Aleman, Paola (2005) "Cluster formation, institutions and learning: the emergence of clusters and development in Chile". Industrial and Corporate Change 14 (4), pp. 651677.

Pinto, Aníbal (1973) Inflación. Raíces estructurales. México D.F: Fondo de Cultura Económica.

Saavedra, Gonzalo (2011) Perspectivas Culturales del Desarrollo en las Costas Australes de Chile. Aproximación Antropológica a las Persistencias y Transformaciones de las Economías de Pesca Artesanal en el Litoral de Aisén. Tesis doctoral, Universidad Complutense de Madrid.

Saavedra, Gonzalo y Macías, Alfredo (2012) "Tradición e innovación en las comunidades de pesca artesanal del sur de Chile: hacia un enfoque reflexivo del desarrollo endógeno”. AIBR, Revista de Antropología Iberoamericana 7 (1), pp. 33-64.

SalmonChile (2007) La contribución de la salmonicultura a la economía chilena. Chile: Departamento de Estudios, SalmónChile.

Sánchez Fernández, Juan Oliver (1992) Ecología y estrategia social de los pescadores de Cudillero. Madrid: Siglo XXI.

Servicio Nacional de Pesca (2012) Anuario Estadístico. Valparaíso: Departamento de Pesca Artesanal.

Staples, Derek y Funge-Smith, Simon (2009) Ecosystem approach to fisheries and aquaculture: Implementing the FAO Code of Conduct for Responsible Fisheries. Bangkok: FAO Regional Office for Asia and the Pacific, RAP Publication.

Sunkel, Osvaldo (1982) Un siglo de historia económica de Chile 1830 - 1930. Dos ensayos y una bibliografía. Madrid: Cultura Hispánica.

Ther, Francisco (2011). "Diversidad y sentido patrimonial: contribuciones desde la antropología del territorio al estudio de las comunidades tradicionales". Terra Plural 5 (2), pp. 153-167.

Urbina, Ximena (2010) “La navegación por los canales australes en la Patagonia occidental insular en los siglos coloniales: La ruta del Istmo de Ofqui”. Magallania 38 (2), pp. 41-67. 